\title{
No Unchallengeable Epistemic Authority, of Any Sort, Regarding Our Own Conscious Experience - Contra Dennett?
}

\author{
Eric Schwitzgebel \\ Department of Philosophy \\ University of California at Riverside \\ Riverside, CA 92521-0201 \\ 9518274288 \\ eschwitz@ucr.edu
}

\begin{abstract}
:
Dennett argues that we can be mistaken about our own conscious experience. Despite this, he repeatedly asserts that we can or do have unchallengeable authority of some sort in our reports about that experience. This assertion takes three forms. First, Dennett compares our authority to the authority of an author over his fictional world.

Unfortunately, that appears to involve denying that there are actual facts about experience that subjects may be truly or falsely reporting. Second, Dennett sometimes seems to say that even though we may be mistaken about what our conscious experience is, our reports about "what it's like to be us" must be correct. That view unfortunately requires a nonstandard and (by Dennett) unremarked distinction between facts about consciousness and facts about "what it's like". Third, Dennett says that reports about experience may be "incorrigible". However, that claim stands in tension with evidence, highlighted by Dennett himself, that seems to suggest that people can be demonstrably mistaken about their own experience. Dennett needlessly muddies his case against infallibilism with these unsatisfactory compromises.
\end{abstract}




\section{No Unchallengeable Epistemic Authority, of Any Sort, Regarding Our Own Conscious Experience}

Dennett contends that we can be mistaken about our own conscious experience. That's clear. 'There is no proposition about one's own or anybody else's conscious experience that is immune to error.... You can't have infallibility about your own consciousness. Period" (2002, p. 13, emphasis in original; also 1991, 2003, 2005). I agree absolutely (see, e.g., Schwitzgebel \& Gordon 2000; Schwitzgebel 2002, 2004, in preparation; Hurlburt \& Schwitzgebel in preparation). But I am greatly puzzled about the way Dennett develops this claim, about certain other claims he stands beside it.

There's a relatively straightforward way to follow through on Dennett's thesis that we can be mistaken about our own conscious experience or "phenomenology". (Dennett endorses the recent practice of using the term "phenomenology" as a generic term for the contents of conscious experience: 1991, p. 45.) Here's what I'd like to say, and what I think Dennett should say about our tendency to err in reporting experience:

There are facts about our conscious experience or "phenomenology". We can be, and (when prompted to reflect) often are, badly mistaken about those facts. Someone who says, for example, that her visual experience is generally flush with precise, stable, photographic detail is simply mistaken about her visual experience. She's not right about one thing, wrong about another. She has no unchallengeable epistemic authority of any sort. One can go wrong about one's conscious experience as easily and as fully as one can go wrong about the objects one sees - perhaps even more easily and more fully. Denying a person authority about her experience doesn't mean, of course, that we can't pay serious attention to what she says, as we might pay serious attention to eyewitness 
testimony in a courtroom prior to deciding whether the witness's report is accurate or not. A subject's testimony about her experience, like the testimony of a sincere eyewitness, is a series of factual claims about objects and events that may or may not really exist as described.

Instead of adopting this relatively straightforward (if controversial) position, Dennett repeatedly takes pains to grant us unchallengeable authority over something, while still recognizing the possibility of error. Thus he says, for example:

If you want us to believe everything you say about your phenomenology, you are asking not just to be taken seriously but to be granted papal infallibility, and that is asking too much. You are not authoritative about what is happening in you [so far, so good - ES], but only about what seems to be happening in you, and we are giving you total, dictatorial authority over the account of how it seems to you, about what it is like to be you (1991, p. 96, emphasis in original).

So let me ask: What is it, exactly, that we have this "dictatorial authority" over?

Several times in his 1991 book, Consciousness Explained, Dennett likens our authority in our statements about our conscious experience to an author's authority over a work of fiction:

As in fiction, what the author (the apparent author) says goes. More precisely, what the apparent author says provides a text that ... goes to stipulate the way a certain "world" is. We don't ask how Conan Doyle came to know the color of Holmes's easy chair, and we don't raise the possibility that he might have got it wrong; we do correct typographical errors and put the best, most 
coherent, reading on the text we can find. Similarly, we don't ask how subjects (the apparent subjects) know what they assert, and we don't (at this point) even entertain the possibility that they might be mistaken; we take them at their (interpreted) word (1991, p. 81, emphasis in original).

Doyle gets unchallengeable authority over the color of Holmes's easy chair at the price of making his claims fictional, not about actual events in the world but about how things stand in some fictional world. So also, the suggestion seems to be, subjects describing their phenomenology get unchallengeable authority over their claims at the cost of our interpreting their claims as not pertaining to how things stand in the actual world. They are making up a story. If the actual flow of their conscious experience differs from the goings-on in the story, no matter. We shouldn't interpret their claims as about the real world of actual conscious experience at all. Accordingly, Dennett writes, later in the book, about novels and analogously about the "text" constituted by subjects' experiential reports: "It's fiction. It seems to be about various fictional ... events, but these events never happened; it isn't really about anything" (1991, p. 366). There is no actual easy chair for Doyle to be mistaken about. When Dennett's imagined interlocutor Otto asks (in response to a brief discussion of how a "heterophenomenological text" is created), "But what about the actual phenomenology?" Dennett answers: "There is no such thing" (1991, p. 365; cf. p. 95).

Now, that last claim is jarring. As I mentioned, Dennett explicitly equates “phenomenology" with the contents of conscious experience, and I don't think he wants to say there is no such thing as conscious experience. Indeed, he wants to make positive claims about it (such as, on the next page, p. 366: "Consciousness is gappy and sparse, 
and doesn't contain half of what people think is there!'). Furthermore, the overall fictionalist position seems to me to be just plainly mistaken. As Dennett acknowledges, people reporting on their conscious experience don't take themselves to be working up fictions. They are making claims about the real world - about that part of the real world constituted by their own conscious experience or phenomenology - claims that they take to characterize that bit of the world accurately. Indeed, if the subjective reporting of experience were really like writing fiction, there'd be no sense in Dennett's claims about people sometimes getting it wrong about their experience. Doyle doesn't, couldn't, get anything wrong about Holmes (though he could lapse into self-contradiction). Dennett himself hints that there's more to the story than pure fictionalism when he adds the parenthetical qualification "at this point" to his claim, cited above (1991, p. 81), that we shouldn't even entertain the possibility that subjects could be mistaken. Of course they can be mistaken, on Dennett's view, as he repeatedly asserts. We can check to see whether the items portrayed in the subjects' reports actually exist as described (e.g., 1991, p. 98). So what's all this business about the claims being fiction and there being no actual phenomenology?

We could say this: Subjects describing their own experience, like eyewitnesses in the courtroom, should be given a chance to characterize events exactly as they see fit. In a certain sense, they have "authority" over their own testimony: They get the definitive and final word regarding their report of the events in question. But this kind of authority is paltry indeed - nothing like "first-person authority" as philosophers generally construe the idea when discussing consciousness - for it says nothing about the epistemic relationship to the events reported. The eyewitness could be totally full of beans, just 
making stuff up, and still have "authority" in this sense. Likewise, we might suggest, the subject's authority, when reporting on her phenomenology, pertains not to the experience itself but only to the report of the experience.

If this is what Dennett means to say, then I agree with him, and only complain that he has put his point infelicitously. There are facts about phenomenology (which is not to say that there are always facts about, for example, precise temporal order and the like; so also in the world of non-mental events). The subjects' statements are to be evaluated as true or false insofar as they accord with those facts. Subjects do not mean to be writing fiction, and it is distortive to reinterpret what they are doing as creating fiction. The key difference between taking subjects' reports as fiction and taking them, instead, as ordinary sincere reports, is that reports but not fictions can be checked for veracity against the real world. (When we say of a false claim that it is "fictional", we are speaking loosely.) It makes better sense, pedestrian though it is, to take the reports exactly as the subjects intend them: As claims - true claims they hope - about their own conscious experience or phenomenology. Subjects are better compared to witnesses on the stand than to novelists.

Let me call attention to the last part of the quote above from Dennett's 1991, p. 96: "we are giving you total, dictatorial authority over the account of how it seems to you, about what it is like to be you'" (emphasis in original). Now I'm going to trouble you to think about a comma, in particular the second comma of that quoted sentence. I've just suggested that the subject's "dictatorial authority", insofar as it exists at all, pertains to her account of her phenomenology, not to the phenomenology itself. I hope that is Dennett's view. And that's how things sound until you hit the comma in question. But 
then, afterward, there's this phrase "what it is like to be you". If you've been reading philosophy of mind much recently, you probably recognize the phrase "what it's like", popularized in Thomas Nagel's celebrated essay "What is it like to be a bat?" (1974). Generally, "what-it's-like-ness" is taken to be identical to phenomenology or conscious experience: There's "something it is like" to be you now as you read this commentary; that "something it's like" consists entirely of, and exhausts, the phenomenology or conscious experience you are having now as you read this commentary. That, in any case, is the standard reading of the phrase Dennett employs here.

Dennett's second comma appears to be a comma of apposition. If so, the sentence can be read in one of two ways: One has "dictatorial authority over the account of how it seems to you, which is to say over the account of what it is like to be you" (emphasis mine), or one has "dictatorial authority over the account of how it seems to you, which is to say dictatorial authority over what is like to be you" (emphasis as in original). The first of these readings accords well with the de-fictionalized interpretation of Dennett that I suggested above. The second seems preposterous: How could having dictatorial authority over an account of something be tantamount to having dictatorial authority over "what it's like to be you", that is to say, over one's phenomenology or conscious experience? As I emphasized above, authority over one's own testimony is quite a different thing from authority regarding the events about which one is testifying.

Unfortunately, the second reading gains support from another passage, which suggests that subjects really are infallible about "what it's like":

To sum up, subjects are unwitting creators of fiction, but to say that they are unwitting is to grant that what they say is, or can be, an account of exactly 
how it seems to them. They tell us what it is like to them to solve the problem, make the decision, recognize the object. Because they are sincere (apparently), we grant that that must be what it is like to them, but then it follows that what it is like to them is at best an uncertain guide to what is going on in them (1991, p. 94).

Bracketing questions about the appropriateness of the word "fiction" here, the most natural reading of this passage seems to involve attributing to Dennett the view that there are facts about "what it is like" to do various things and that subjects in reporting their phenomenology do accurately convey those facts, even if they go wrong about "what is going on in them" (N.B. compare this last phrase to a similar phrase in the quote from $\mathrm{p}$. 96 above). Is the idea that subjects always get it right about "what it is like" but often go wrong about their conscious experience? If so, that seems to imply that besides facts about conscious experience there are, in addition, distinct and sometimes contrary facts about "what it is like". What would be the difference between the two species of fact? And why should we be so uncharitable as to interpret subjects' claims as inaccurate attempts to convey facts of the first sort, or even mere fictions, rather than accurate attempts to convey facts of the second sort? Trying to make sense of this, I get a headache. Now, could I be mistaken in my sincere judgment about the presence of the phenomenology of pain in my head, yet still correct that in some sense "it is like" I have a headache? My headache worsens.

Here's an inadequate attempt to make sense of this: When my five-year-old son Davy opens the refrigerator, he notices the light is always on. Therefore he says "the refrigerator light is always on". His claim is false, but we still could say that in a certain 
sense it's like the refrigerator light is always on, since it's always on when one checks it or needs it to be on. So Davy is wrong that the light is always on but right that it's like the light is always on. Similarly, perhaps, we could say that although our visual experience is much gappier and sketchier than most people suppose, nonetheless $\underline{\text { it's like }}$ our visual experience is a plenum, since a plenum of visual information is available to us at any moment. So we're wrong about our experience but still right in some sense about what it's like.

This interpretation of Dennett is inadequate, I think, for two reasons. First, it puns on "what it's like", conflating the phenomenal sense of the phrase with the similarity sense. The phrase "what it's like to be you" is ordinary meant to pick out your phenomenology or conscious experience. It does not refer to what being you resembles. But in the refrigerator light use of "it's like" above, the word "like" functions to pick out a resemblance: The refrigerator light isn't always on, but the actual state of affairs in an important way resembles the state of affairs in which the refrigerator light is always on, in that it is always on when you need it. As far as I recall, Dennett flags no special use of "what it's like" at variance with the standard phenomenal (not resemblance) use of that phrase. On the contrary, he seems to use "what it is like to be X" and " $X$ 's consciousness" interchangeably in a number of places - for instance in a quote I will shortly be presenting from a 2002 paper and in his section "What it is like to be a bat" (1991, p. 441-448).

Second, if there are facts about visual experience's being like a plenum in certain respects - for example, in that a mass of information is swiftly available - those are fairly complicated and subtle facts regarding the relationship between properties of actual 
experience and some hypothetical condition. It's out of line with Dennett's prudent skepticism to grant subjects arbitrary authority regarding such facts. We shouldn't expect people to be infallible in their judgments of resemblance.

So I'm baffled. I hope I'm not being dense and uncharitable. Help me out, Dan! It seems to me also that in some places Dennett makes a very different kind of effort to give us authority about our own experience, most notably in his "The case for rorts" (2000), where "rorts" (named after Richard Rorty) are "incorrigible reports". Dennett summarizes the view nicely in a slightly later paper:

You can't have infallibility about your own consciousness. Period. But you can get close.... Once you have an intentional system with a capacity for communicating in a natural language, it offers itself as a candidate for the rather special role of self-describer, not infallible but incorrigible in a limited way: It may be wrong, but there may be no way to correct it. There may be no truth-preserving interpretation of all its expressed opinions ... about its mental life, but those expressed opinions may be the best source we could have about what it is like to be it. A version of this idea was made (in-)famous by Richard Rorty ... and has been defended by me more recently (2002, p. 1314).

Here Dennett appears to be talking not about the kind of dictatorial authority a fictionwriter has over his creations (or a witness over his testimony): We wouldn't want to say that although Doyle is the best source we have about Holmes, he still may be wrong about the color of Holmes's easy chair. It's more like this: You're the only person who has ever visited the Isle of Noo-Na. When you come back and report on the plant life 
there, you are automatically the best authority on it. You may be wrong, but there's no way anyone else could correct you. Here's Rorty's definition: “ㅗ believes incorrigibly that $\underline{p}$ at $\underline{t}$ if and only if (i) $\underline{S}$ believes that $\underline{p}$ at $\underline{t}$ (ii) There are no accepted procedures by applying which it would be rational to come to believe that not- $\underline{p}$, given $\underline{S}$ 's belief that $\underline{p}$ at t” (1970, p. 417). Incorrigibility in the relevant sense is thus the claim that we could never rationally believe that a person is mistaken about her own experience, regardless of whether she is actually mistaken or not. Though that's not quite infallibility, it's still strong stuff!

I really don't think Dennett should want to say this about conscious experience (or about "what it's like to be you", if that's any different). Take the Isle of Noo-Na. You may be the best authority, but we go too far if we say that there is no way ever to correct you. Suppose you report that there's a flower there with a certain internal structure that you describe in some detail. Unbeknownst to you, very similar flowers grow on betterknown islands nearby. A consensus of experts has noted that all previously observed flowers of that genus have an internal structure very much like the one you reported, but different in one key feature. Compelling theoretical reasons exist to suppose little species-to-species variation in that feature and no significant likelihood of mutation in that direction. Furthermore, there's an easy psycho-perceptual explanation of how an amateur could erroneously misperceive such a feature. Weighing all these facts, the most reasonable thing may be to correct your report, even over your strenuous objection. Strictly speaking, then, your report is "corrigible" after all.

Why shouldn't the same be true for our reports of our experience? Dennett emphasizes that others often know more about what is going on in the subjects' heads 
than the subjects themselves do, and that this can be key to learning about their consciousness (e.g., 2002, p. 16). Couldn't a good enough conspiracy of such outside knowledge justifiably overthrow and "correct" a subject's report? Isn't that, in fact, exactly what Dennett does so admirable a job of providing in his treatment of vision in Consciousness Explained (1991)? People who claim they experience a wealth of detail in visual experience, far out to the periphery, are mistaken; their reports are not only corrigible by external evidence, but demonstrably false. It turns out ordinary people aren't such great authorities on what it's like to see.

In sum: I want to read Dennett as saying (as I say) that there are facts about conscious experience, and that people often get these facts wrong, even when it's their own ongoing conscious experience at issue; and that although (obviously) each of us stands in some special relationship to her own experience, that special relationship confers upon us no unchallengeable authority about it. Dennett puzzles me when he asserts, on the contrary, that we can have some unchallengable authority, despite our aptitude for error and the apparent availability of methods for outsiders to detect and correct those errors. Perhaps he only means that we have the kind of authority a witness has over her testimony, which is to say no authority at all over the events described, only authority over one's description of them. But Dennett seems to want something stronger than that when he (1.) likens the authority to an author's authority over his fictional creations, where there is no possibility of factual error because there are no real-world facts being reported, (2.) claims that subjects "must" be right in their sincere reports about "what it's like", and (3.) claims that subjects' reports about their experiences can be “incorrigible" in Rorty’s sense. 
Dennett thus muddies his case against infallibilism. He need make no such

compromises. People have no unchallengeable authority, of any sort, about their own experience. They err about that, as they err about anything, plain and simple. 


\section{References:}

Dennett, Daniel C. (1991). Consciousness explained. Boston: Little, Brown, and Company.

Dennett, Daniel C. (2000). The case for rorts. In R.B. Brandom, ed., Rorty and his critics. Malden, MA: Blackwell.

Dennett, Daniel C. (2002). How could I be wrong? How wrong could I be? Journal of Consciousness Studies 9, no. 5-6, 13-16.

Dennett, Daniel C. (2003). Who's on first? Heterophenomenology explained. Journal of Consciousness Studies 10, no. 9-10, 19-30.

Dennett, Daniel C. (2005). Sweet dreams. Cambridge, MA: MIT.

Hurlburt, Russell T., \& Schwitzgebel, Eric (in preparation). Describing inner experience? Proponent meets skeptic.

Rorty, Richard (1970). Incorrigibility as the mark of the mental. Journal of Philosophy $\underline{67,} 399-424$.

Schwitzgebel, Eric (2002). How well do we know our own conscious experience? The case of visual imagery. Journal of Consciousness Studies, 9, no. 5-6, 35-53.

Schwitzgebel, Eric (2004). Introspective training apprehensively defended: Reflections on Titchener's lab manual. Journal of Consciousness Studies, 11, no. 7-8, 58-76.

Schwitzgebel, Eric (in preparation). The unreliability of naive introspection.

Schwitzgebel, Eric, \& Gordon, Michael S. (2000). How well do we know our own conscious experience? The case of human echolocation. Philosophical Topics 28, 235-246. 